\title{
Hic sunt dracones: Here be dragons! Difficulties in mapping the demand for social work placements in New Zealand
}

\section{Dr Kathryn Hay ${ }^{1}$, Neil Ballantyne ${ }^{2}$, and Karin Brown ${ }^{3}$}

\begin{abstract}
Anecdotal evidence suggests that the growth in demand for social work field placements in New Zealand is outstripping supply and impacting on placement quality. However, to date, no systematic study of placement demand or supply in New Zealand has been published. Our study sought to identify the number of students placed during 2012, their placement setting (government or non-government), whether they were supervised by a Registered Social Worker (RSW), and whether they had on-site supervision. It combined secondary analysis of the annual reports of recognised programmes to the Social Workers Registration Board with a survey of seven tertiary institutions. We found that students placed in government settings were three times more likely to experience on-site supervision by an RSW, but that the majority of placements were in non-government settings. The study also uncovered significant problems with the integrity of the annual report data collected and recommendations for improvements are outlined in this article.
\end{abstract}

Keywords: practice placements; social work education; New Zealand

1. Director of Field Education/Senior Lecturer

2. Director, Learning Designs

3. Programme Leader, Open Polytechnic

Address for correspondence: Dr Kathryn Hay, Massey University, Private Bag 11-222, Palmerston North, New Zealand. k.s.hay@massey.ac.nz

24 J. of Practice Teaching \& Learning 13(1), pp.24-43. DOI: 10.1921/12302130106. @ w\&b 2014 


\section{Background}

Compared to modern map-makers medieval cartographers had limited information on which to base their maps, and what information they had was not always reliable (Harley \& Woodward, 1987). In the uncharted parts of maps they often included images of dragons or sea serpents to denote danger and warn travellers of unknown territory. Some maps included the Latin phrase 'Hic sunt dracones', or 'Here be dragons'. In using this metaphor of maps and mapping in the title of our study we wanted to signal the importance of mapping and quantifying the demand and supply of placements prior to deeper exploration of other placement issues such as quality. However, as discussed below, the mapping metaphor became even more significant as we explored the data, and uncovered the many data dragons concealed inside.

Field placements have long been a prominent and significant feature of social work tertiary education in New Zealand. From the inaugural training programmes in the 1960s, practice experience within the field of social work has been recognised as a critical means of enabling students to integrate classroom learning with the realities of the field (Nash, 1998). Field placements have been described as the signature pedagogy (Wayne, Bogo, $\&$ Raskin, 2010) and the heart of social work education (Homonoff, 2008). They are critical '...for developing practice skills and socialising the student into social work professional roles' (Elpers \& FitzGerald, 2013, p. 289-290).

However, providing students with high quality practice placement depends, in part, on the relationship between placement supply and demand. Since the 1990s the number of social work programme providers has proliferated from thirteen providers in 2008 to the current seventeen tertiary providers offering undergraduate and/or postgraduate social work programmes (Nash, 1998). These Tertiary Education Institutions (TEIs) provide social work programmes recognised by the regulatory body, the Social Workers Registration Board (SWRB). The training providers include five universities, two Wānanga (a TEI that provides education in a Maori cultural context), and ten polytechnics. A combination of local and distance institutions allow students across New Zealand to access opportunities for social work education. Between 2007 and 2011 the overall growth per annum of graduates of social work programmes in New Zealand was 14\% (TEC, 2012). The projected growth in graduates for the period 2012-2016 is estimated to be $40 \%$ per annum (TEC, 2012). These figures highlight the importance of mapping and planning for the expected increase in demand,

25 J. of Practice Teaching \& Learning 13(1), pp.24-43. DOI: 10.1921/12302130106. @ wEb 2014 
not only for social work training, but also for practice placements.

Since each student is required to undertake a minimum of 120 days of supervised practice during their qualification growth in the number of programmes, and the consequential growth in student numbers (from 370 placements in 2008 to 1374 placements in 2012 (Duke, 2014)), has led to an increased demand on social service agencies for practice placements. The majority of undergraduate and postgraduate placements are for a combined 120 day period. Given the size of the social services sector in New Zealand (the SWRB estimate there are around 6000 social workers in practice who could meet the criteria for registration (SWRB, 2011, p. 8)) and the growing demands on the workforce, there are questions to be asked about the sustainability of placement supply. Anecdotally, some TEIs have begun questioning whether there will be sufficient placements available for all enrolled students in the future.

With these questions and concerns in mind we sought to map the current demand for social work practice placements in New Zealand. The following section discusses some of the challenges to field education within social work and the broader disciplinary context. The methodology of the project is then outlined prior to the presentation of the results. We conclude by summarising our recommendations for improvements to the routine data collection practices of the SWRB.

\section{Literature review}

The rise in tertiary programmes that incorporate field education is apparent both in New Zealand and internationally and extends across other professional disciplines such as nursing, speech language therapy and the sciences. Bates, Bates, \& Bates (2007) explain that this changing environment 'has occurred as professions have increased their demands for credentialing and as new professional occupations emerge in the "knowledge society"' (p.121). Field education is at the interface between practice and the academy and provides a unique opportunity for students to experience first-hand the skills, methods of practice and use of knowledge in both contexts (Chilvers \& Hay, 2011; Giles, Irwin, Lynch, \& Waugh, 2010). While the testing and integration of classroom learning in real-world practice settings is educationally desirable, and welcomed by students, there are associated challenges for academic staff and agencies in maintaining

26 J. of Practice Teaching \& Learning 13(1), pp.24-43. DOI: 10.1921/12302130106. @ w w 2014 
an adequate supply of effective supervised practice placements (Cleak \& Wilson, 2013; Wilson, 2012).

One challenge facing academic staff is the opportunity cost to field placement scarcity. In New Zealand it is common practice across the TEIs for academic staff to liaise between social service agencies and students, following a process of matching the preferences of both stakeholders and confirming a placement once an interview with agency staff and students has been undertaken. When under pressure to compete with other providers for placements, academic staff may feel it necessary to spend less time on this matching process so as to ensure students are placed quickly. This approach may be haphazard and focus less on what type of work and agency context individual students are best suited for thus impacting on the likelihood of successful learning (Bates et al., 2007; Coll \& Eames, 2000). The importance of ensuring a good match between the student, their placement supervisor, and placement learning opportunities is well-documented (Coll \& Eames, 2000; Hastings, 2010; McDermott, 2008). The responsibility for placing students lies with the tertiary provider and therefore "partnership and communication between the educational institution, students and employers must be strongly established, so that the context of the work place and the opportunities that it provides for the student learning are clearly understood by all parties' (Eakins, 2000, p.66 cited in McDermott, 2008, p.103). Having less time to secure appropriate placements for students and communicate effectively with agency managers and either the on-site or off-site supervisors may have a detrimental effect on the overall success of the placement.

From the perspective of social service agencies, competing placement requests from different TEIs can add pressure to organisations already under strain, leading some to manage demand by aligning themselves with particular TEIs, thus limiting the range of placement opportunities for others. Agencies expect that TEIs will prepare students with a beginning level of competence before entering placement (Elpers \& FitzGerald, 2013). However, curriculum differences between institutions may sometimes serve to advantage some TEIs over others, depending on the perceptions and preferences of individual agencies. Some agencies may also be inclined to select final year students who are perceived to be further advanced in terms of their practice skills and theoretical knowledge, thus limiting options for students who do not fit these criteria.

Gatekeeping is a challenging feature of field education and acknowledged as 'a necessary, ethical and mandated role for social work education' (Elpers

27 J. of Practice Teaching \& Learning 13(1), pp.24-43. DOI: 10.1921/12302130106. @ w\&b 2014 
\& FitzGerald, 2013 pp. 292-293). Gatekeeping practices may include developing and implementing policies and regulations, upholding academic and professional standards, challenging unsuitable or unethical student conduct, preventing students going on placements or removing them if unprofessional behaviour occurs (Apaitia-Vague, Pitt \& Younger, 2011; Elpers \& FitzGerald, 2013). In order to sustain placement opportunities TEIs rely on maintaining positive relationships with social service agencies. If competition for placements is strong then gatekeeping practices may be increased so as to protect the reputation of both the TEI and the student, for example students may be required to pass tighter criteria about being fit for placement. Agencies in turn may prefer to take students whom they know have been well-prepared academically and professionally and who are more likely to contribute effectively to the work of the organisation. Students who are seen to be more 'challenging' may have to work harder to demonstrate they are ready to undertake the placement. While this may contribute to better placement experiences for some agencies, clients and the student, it may also restrict a student's movement through their qualification pathway.

The requirements of regulatory bodies can also have a direct influence on placement supply and demand creating tensions between TEIs, students and agencies (Chilvers \& Hay, 2011; Wilson, 2012). In New Zealand the SWRB, for instance, requires students to undertake a minimum of two placements in two different organisational settings and two different fields of practice. While the intention is to enable students to broaden their practice experience and ability to work with different clients, these constraints place pressure on TEIs to identify placements capable of meeting the SWRB requirements. Further, SWRB regulations stipulate that students may complete only one placement within their place of employment and that all students must be supervised by a registered social worker (RSW). Once again, these requirements may support a robust learning experience but they also create challenges for TEIs struggling to find placement opportunities in varied geographical, cultural and urban/rural areas. The requirement to ensure students are supervised by a RSW is particularly challenging in the context of New Zealand's current regulatory regime where registration is not required by all social service organisations.

The relationship between quantity and quality in field education is complex. It seems reasonable to assume that increased demand might lead to reductions in placement quality (Moorhouse, 2013; Wilson, 2012). However, placement quality is likely to be perceived differently by placement

28 J. of Practice Teaching \& Learning 13(1), pp.24-43. DOI: 10.1921/12302130106. @ w w 2014 
stakeholders. Employers, regulators, educators and students are likely to have divergent perspectives (Chilvers, 2011; Moorhouse, 2013). From the point of view of the SWRB, several of the required indicators of placement quality are expressed within the policy document 'Practicum for a recognised social work qualification' (SWRB, 2013). These include that 'All placements must have supervision provided by fully registered social workers' (p.3), and that 'At least one placement will be supervised on-site by a fully registered social worker' (p.3). The second requirement includes the caveat that, while the registration of social workers in New Zealand continues to be voluntary, achieving on-site supervision by a RSW may not be possible. In the situation where a RSW is not available within the agency to supervise a student TEIs will organise off-site supervision with a RSW. Off-site supervision may occur with an individual RSW located within the local community; on campus with an academic staff member who is a RSW; or within a group either on or off campus. As supervision then occurs away from the agency, a non-social work staff member within the agency will be assigned the role of field educator for the purposes of supporting and mentoring the student on a day to day basis and liaising with the TEI.

At present there is no requirement by the SWRB for students to have placements in either government or non-government organisations. Government organisations include Child Youth and Family (a service line for the Ministry of Social Development); hospitals (District Health Boards), Probation Services, local government (City or District Councils) and Government Ministries. Non-government organisations are social service organisations that may or may not be funded by the government to undertake services in communities.

As the first step in a larger research programme aimed at measuring and improving the quality of social work placements in New Zealand, this study was designed to quantify the demand (and some aspects of the supply) of placements during the academic year 2012. The specific research questions addressed in this paper are:

1. How many students were on placement during 2012?

2. What proportion of students were placed in government and nongovernment settings?

3. What proportion of students were supervised by RSWs?

4. What proportion of students were supervised by on-site supervisors?

5. What proportion of students had supervisors who were both on-site and RSWs?

29 J. of Practice Teaching \& Learning 13(1), pp.24-43. DOI: 10.1921/12302130106. @ w\&b 2014 


\section{Methodology}

The study is primarily quantitative and descriptive in nature and aimed to produce a snapshot of placements used during the academic year 2012. We used two different methods of data collection: a) a self-completion questionnaire survey of all TEIs using placements during 2012; and b) secondary analysis of SWRB Annual Report data collected for 2012. The survey method enabled control over the way in which questions were asked and allowed the researchers to ask additional questions not included in the routine SWRB Annual Report template. However, the SWRB data, since it was a requirement of all recognised providers, offered a more complete data set and a source of data triangulation (Bryman, 2012).

\section{The survey}

A request for data from the 2012 period was sent by letter (and email) to the Director of Social Work, or the person coordinating placements, at each of the TEIs with social work programmes and who were having placements during 2012 (15 in total). TEIs received a letter inviting them to participate in the research, accompanied by a hard-copy of the survey. This letter was then followed by an email with a link to the online version of the survey to facilitate electronic submission of information. Potential participants therefore received two invitations to participate and had a choice to respond on paper or electronically. Any paper-based surveys received were entered into the electronic survey to ensure consistent analysis. Table 1 shows the number of survey participants by TEI type and the number and proportion of TEIs who participated.

The survey included twenty-three questions only two of which required open-ended responses. The questions with open-ended responses focussed on reasons why students could not be placed and reasons for placement terminations: they are not included in this analysis. We estimated it would take respondents a maximum of thirty minutes to complete the questionnaire. To collect the (mostly) numerical data required to answer our research questions there are few disadvantages to the use of a selfcompletion survey. It assumes that respondents have access to the data required, that they are clear about the nature of the responses required, and that they have the time and commitment to participate. The only significant disadvantage is the potential for bias introduced into data if the response

30 J. of Practice Teaching \& Learning 13(1), pp.24-43. DOI: 10.1921/12302130106. @ w w 2014 
rate is low. This was a particular concern in this study when institutions are so diverse in terms of student numbers, geographical locations, and access to agency networks. As noted in Table 1 only $47 \%$ of TEIs participated and no Wānanga participated.

\section{The SWRB Annual Reports}

To supplement the survey data, the researchers contacted the Deputy Registrar of the SWRB and requested access to data provided by TEIs in their annual reports to the SWRB for the year 2012. These annual reports began in 2008 and have occurred every year since. They are used to provide a snapshot report to the SWRB (J. Duke, personal communication, September 13, 2013). A confidentiality agreement was signed by the researchers before any data was accessed. The reports covering the year 2012 were copied, identifying information was obscured, and the data was collated and analysed.

The SWRB annual report data included all of the TEIs offering placements during 2012 and was therefore a more complete data source. Secondary analysis of official statistics has both advantages and disadvantages (Bryman, 2012; Smith, 2008). The advantages include that data are collected on a whole population rather than a sample; data are routinely collected and so the study can be considered to be less obtrusive; data are not prone to a 'reactive effect' where participant responses may be influenced by the awareness of being studied. On the other hand, secondary analysis of official data includes the following limitations: data collected for the purposes of audit may be influenced by attempts on the part of the audited to manage impressions (Power, 2003); since the data are not collected for the purposes of empirical research the operationalisation of definitions may be less rigorous, influencing data reliability and validity; key variables of interest to researchers may be missing (Bryman, 2012; Smith, 2008).

\section{Ethics}

Ethical approval was sought from Massey University's Human Ethics Committee and granted under the low-risk category. No harm to participants, TEIs or researchers was anticipated, nor was any conflicts of interest identified.

31 J. of Practice Teaching \& Learning 13(1), pp.24-43. DOI: 10.1921/12302130106. @ w\&b 2014 


\section{Results}

In this section we use descriptive statistics to compare data from both of the data sources. There are, however, significant problems with comparing these two sets of data which we explore in the discussion section below.

\section{Types of placement agency used}

As shown in Table 2 below, the SWRB annual report data identified that $70 \%$ of placement agencies used were non-government agencies and 30\% government agencies. The survey data sample, shown in Table 3, also shows a greater proportion of non-government placements used although the difference is smaller with $55 \%$ of placements in non-government agencies and $45 \%$ in government agencies.

One possible explanation for this difference (apart from bias introduced by the limited sample size in the survey) is that the two datasets used different questions to collect data. Whilst the survey asked respondents to indicate the number of placements used by placement agency type, the SWRB form asked respondents to indicate the number of placement agencies used. Since, a TEI will often place a number of students within the same agency it is possible that respondents interpreted this question to mean agencies used rather than individual student placements.

That this was sometimes the case is suggested by Table 4 with data from the SWRB annual reports identifying whether student supervisors were located in government or non-government agencies. Table 4 shows that the reported number of supervisors was higher $(\mathrm{N}=1613)$ than the number of placement agencies used $(\mathrm{N}=1002)$, and that the proportion of supervisors in non-government agencies (66\%) and government agencies (34\%) is closer to the proportions of placement types found in the survey data. However, we must be cautious about assuming that the number of supervisors used (as reported in the SWRB annual report data) is equal to the number of student placements. In the absence of instructions on how to enter data into the SWRB annual report template, it is possible that respondents included more than one supervisor for some students. For example, where a student had a non-RSW on-site supervisor responsible for day-to-day supervision, and an off-site RSW for professional supervision; or where a student had a cultural supervisor in addition to their professional supervisor.

32 J. of Practice Teaching \& Learning 13(1), pp.24-43. DOI: 10.1921/12302130106. ๑ w\&b 2014 


\section{Supervision by Registered Social Workers}

As noted above, one of our research questions concerned the proportion of students supervised during placement by RSWs. Drawing on the SWRB annual report data, Table 5 shows that government agencies had a significantly higher proportion of RSW supervisors (76\%), compared with non-government agencies (42\%).

The survey data, shown in Table 6, indicates a higher proportion of RSW supervisors in both placement agency types (with 85\% of RSW supervisors in government agencies, and 53\% in non-government agencies). However, the difference in the proportions of RSW supervisors to non-RSW supervisors is remarkably similar in both data sources: the SWRB annual report data indicates that there are 34\% more RSW supervisors located in government agencies; and the survey data indicates a difference of $32 \%$.

\section{On-site Supervision}

The two tables in this section draw on the two datasets to indicate the number and proportion of supervisors who were on-site supervisors situated within the placement agency or off-site supervisors from another agency setting. In Table 7 the SWRB annual report data show that the overall proportion of on-site supervisors was $79 \%$ with government placement agencies having a slightly higher proportion of on-site supervisors (82\%) than non-government placement agencies (78\%).

The survey data shown in Table 8 indicate a lower overall rate of onsite supervision of $67 \%$. As in the SWRB annual report data the on-site supervision rate is higher for supervisors based in government settings (75\%) than non-government settings (59\%). However, the difference between the two placement agency types is greater in the survey data than in the SWRB annual report data: in the SWRB data there is a small difference in on-site supervision rates between placement types of $4 \%$, whereas the difference is $16 \%$ in the survey data.

\section{On-site RSW supervision}

The expressed preference of the SWRB is that a student must have at least one experience of on-site supervision by an RSW. The data from the

33 J. of Practice Teaching \& Learning 13(1), pp.24-43. DOI: 10.1921/12302130106. @ w\&b 2014 
SWRB annual reports indicates that $38 \%$ of supervisors were on-site RSWs. However, government agency settings were almost three times more likely to have on-site RSW supervisors (66\%), than non-government settings (23\%). Although the survey data included the number of on-site supervisors and the number of RSWs these variables were not cross-referenced and so there is no survey data for on-site RSW.

\section{Discussion}

In this section, based on the two sets of data reported above, we discuss our conclusions, the implications for the supply and demand of social work placements in New Zealand, and the limitations of the study.

\section{Placement demand}

It seems reasonable to begin any discussion about placement demand with an accurate statement of the number of placements used by TEIs. The data from the SWRB annual reports indicate that, during 2012, there were 1002 placement agencies used, and 1613 supervisors allocated. However, since placement agencies may accommodate several students, and since a student may have more than one supervisor (an off-site RSW or additional cultural supervisor), neither of these figures is equivalent to the number of student placements. The survey questionnaire did ask for the number of placements used $(\mathrm{N}=493)$ as well as the number of supervisors $(\mathrm{N}=498)$ with a difference of only five. Since the survey response rate was $47 \%$ of TEIs using placements we might assume the actual number of placements used is closer to 1000 than 1600 . However, the survey response rate combined with the diversity of individual TEIs prevents us from making this inference. In retrospect, analysis of the two data sets would have been facilitated if some of the survey questions had reflected the SWRB Annual Report data; however this presumes that the SWRB Annual Report questions were already enabling valid data collection. As discussed shortly this was not the case.

Of course, the number of placements used, although important, does not of itself, reveal anything about future anticipated growth in demand. The survey questionnaire attempted to address this, from the TEIs point

34 J. of Practice Teaching \& Learning 13(1), pp.24-43. DOI: 10.1921/12302130106. @ w\&bb 2014 
of view, by asking an additional question about the estimated number of student placements required during the following academic year of 2013. In response to this question, across all seven of the participating TEIs, there was a mean anticipated increase of $12 \%$ for 2013 . However, this mean percentage increase masks considerable differences between institutions in estimated future demand: two of the seven surveyed TEIs anticipated requiring fewer placements; one anticipated the same number; and four anticipated a greater number with one outlier TEI anticipating an increase of $62 \%$. The differences between institutions in anticipated demand suggests that efforts to coordinate supply and demand need to take cognisance of local factors and to consider local planning mechanisms.

\section{Placement settings: government and non-government}

The SWRB data shows a higher proportion of non-government agencies used for placements (70\%), and a higher proportion of non-government supervisors allocated (66\%). In the survey data, the difference between the two settings is less marked, but at 55\%, non-government placements are still higher. The question is whether this disproportionate use of nongovernment placements is a matter for concern? Chilvers (2011) cites a report of a survey of New Zealand social workers carried out by the Tertiary Education Commission in 2009 (TEC, 2009) where '... survey participants indicated concern for the quality of field education, particularly in the non-government organisation (NGO) sector' (pp. 76-77). The basis for this concern is not made clear but it was also noted that, at the time of the survey, non-government placements constituted $43 \%$ of placement settings. Our data suggests that the proportion of non-government placements used may be increasing.

Although, the SWRB requires that a student should experience placements in two contrasting settings and that the final placement should be one where all ten of the SWRB competence standards are met, the indicators stop short of requiring that a placement should occur within a statutory context, or even that a student is required to undertake statutory work. While our findings suggest the majority of practice placements are located in the non-government sector, it does not follow that these students have no access to statutory tasks, nor does it necessarily reflect on the overall quality of the placement experience. However, maintaining an optimum balance between government and non-government settings seems desirable

35 J. of Practice Teaching \& Learning 13(1), pp.24-43. DOI: 10.1921/12302130106. @ w\&b 2014 
if TEIs are to be able to offer students a range of contrasting settings. A more detailed, comparative study of the quality of placement experiences in both settings might help to clarify the opportunities and limitations of government and non-government placements.

\section{On-site supervision by an RSW}

Although the preponderance of non-government settings does not necessarily limit access to statutory tasks our data suggests that placement in a non-government setting has an impact on two of the quality indicators of the SWRB: supervision by an RSW; and on-site supervision. Specifically, during the focal year of the study, students placed in government settings were more likely to be supervised by an RSW, more likely to have an on-site supervisor, and almost three times as likely to have a supervisor who is both an RSW and available on-site.

In many respects this finding is a reflection of the non-mandatory registration context in New Zealand and of the differential incentives for registration operating in government and non-government sectors. Based on data from the 2006 New Zealand census the SWRB (2011) estimate there are approximately 6,000 social workers working in New Zealand who could meet the criteria for registration. Forty percent of them work in government settings ( $N=2,400)$, and $60 \%$ in non-government settings $(N=3,600)$. Yet of that number only $19 \%(\mathrm{~N}=697)$ of the registerable non-government workforce are registered, compared with $90 \%(\mathrm{~N}=2,148)$ of the registerable government workforce (SWRB, 2011). As far as we are aware, no studies have been done to account for the different registration rates in the two settings but factors might include a requirement that workers be registered in government settings, a more positive view of the benefits of registration in government settings, and a greater willingness of government employers to meet the costs of registration.

Being supervised by an RSW is a quality indicator for the SWRB, and it does assure that supervisors have been assessed against key practice competencies. However, we cannot assume that being supervised by an RSW will, of itself, guarantee a higher quality learning experience for the student. This might be a fruitful area for future research with a more qualitative focus. Equally, our study is silent on the implications for quality of the off-site supervision experienced by $21 \%$ of student in the SWRB data set. However, we note with concern the recent findings of an Australian

36 J. of Practice Teaching \& Learning 13(1), pp.24-43. DOI: 10.1921/12302130106. @ w w 62014 
study where social work students reported high levels of dissatisfaction with off-site supervision (Cleak \& Smith, 2012). This too is an area where a qualitative research inquiry might prove illuminating.

\section{Limitations of the findings and recommendations regarding the SWRB Annual Report data}

The low survey response rate is problematic in a population of institutions where each one differs significantly (in terms of student numbers, urban and rural settings, and access to employer networks). Although the SWRB annual report data is, as we would expect, far more complete than our survey sample, there were significant problems with data integrity. For example, there were many instances where the table used to collect the data had missing values; instances where tables had been altered to accommodate the specific circumstances of the TEI making the data difficult to interpret; and cases where sums of values did not tally as expected. The data had been collected for a different purpose and so it is to be expected that the information it contained would not exactly match our research goals. The resulting data integrity issues do raise questions as to the utility of the current compulsory data collection process. The greatest threat to the reliability of the SWRB data was that, in the absence of instructions on how to complete the table, questions were open to interpretation in different ways.

In our view the SWRB annual report data has the potential to be the source of a national placement data set that could be used to map longitudinal trends in placement demand and supply over time. With appropriate adjustments it could help to identify localities where placement demand was particularly high and where new approaches might be required. It could assist in tracing movement towards desired outcomes such as the provision of on-site RSW supervision. It could even help to identify possible issues with the profile of failing students. If aggregate data was published annually, and shared with employers and educators, it could be used to improve local placement supply coordination and contribute to improved national workforce planning. This potential could be achieved with a few simple changes to the design of the data collection instrument, the inclusion of instructions on data entry (with clear definitions of variables), and a commitment to clarify and clean the data prior to publication. The SWRB have invited the research team to discuss changes to their data collection processes.

37 J. of Practice Teaching \& Learning 13(1), pp.24-43. DOI: 10.1921/12302130106. @ w\&b 2014 


\section{Conclusion}

The primary finding of this paper is that before conclusions can be drawn about placement demand and supply (a necessary precursor of the analysis of placement quality) improvements are required in the quality and integrity of the annual data collected. Therefore, we recommend changes to the way in which the SWRB collects placement data in order to: establish a robust national placement data set; enable more effective placement planning and coordination; and contribute to national level workforce planning. The success of national workforce planning is highly reliant on the ability of the educators, the SWRB and the agencies that provide placements to work together towards shared outcomes. We recommend not only improvements in the SWRB data collection process but also crossinstitutional conversations on collaborative and innovative approaches to organising and sustaining effective placements.

Ultimately, the map of placement demand in New Zealand still contains many 'dragons' and unanswered questions remain. Some simple improvements to the national data collection system would enable better mapping of the social work placement environment. At the same time, qualitative studies are required to illuminate the value of on-site and off-site supervision, and to clarify how RSW status might be a driver of improved supervisory practice.

\section{References}

Apaitia-Vague, T., Pitt, L. and Younger, D. (2011) 'Fit and proper' and fieldwork: A dilemma for social work educators? Social Work Review, 23, 4, 55-64

Bates, A., Bates, M., and Bates, L. J. (2007) Preparing students for the professional workplace: Who has responsibility for what? Asia Pacific Journal of Cooperative Education, 8, 2, 121-129

Bryman, A. (2012) Social research methods (4th ed.). Oxford, England: Oxford University Press

Chilvers, D. (2011) Improving the quality of social work field education: The efficacy of an analysis using Cultural-Historical Activity Theory. Social Work Review, 23, 4, 76-86

Chilvers, D. and Hay, K. (2011) Editorial. Aotearoa New Zealand Social Work, 23, $4,1-2$

38 J. of Practice Teaching \& Learning 13(1), pp.24-43. DOI: 10.1921/12302130106. @ wEb 2014 
Cleak, H. and Smith, D. (2012) Student satisfaction with models of field placement supervision. Australian Social Work, 65, 2, 243-258

Cleak, H. and Wilson, J. (2013) Making the most of field placement (3rd ed.). South Melbourne, Australia: Cengage Learning

Coll, R. K. and Eames, C. (2000) The role of the placement coordinator: An alternative model. Asia-Pacific Journal of Cooperative Education, 1, 1, 9-14

Elpers, K. and FitzGerald, E. A. (2013) Issues and challenges in gatekeeping: A framework for implementation. Social Work Education, 32, 3, 286-300

Giles, R., Irwin, J., Lynch, D. and Waugh, F. (2010) In the field: From learning to practice. South Melbourne, Australia: Oxford University Press

Harley, J. B. and Woodward, D. (Eds.). (1987) The history of cartography: Cartography in prehistoric, ancient and medieval Europe and the Mediterranean, Vol. 1. Chicago: University Of Chicago Press

Hastings, W. (2010) Expectations of a pre-service teacher: implications of encountering the unexpected. Asia-Pacific Journal of Teacher Education, 38, 3, 207-219

Homonoff, E. (2008) The heart of social work: Best practitioners rise to challenges in field instruction. The Clinical Supervisor, 27, 2, 135-169

McDermott, K. (2008) Addressing the weak link: enhancing support for the sponsors of student placements in cooperative education. Asia-Pacific Journal of Cooperative Education, 9, 1, 91-111

Moorhouse, L. (2013) How do social work students perceive their fieldwork supervision experiences? (Unpublished masters thesis). Massey University, Palmerston North, New Zealand

Nash, M. (1998) People, policies and practice: Social work education in Aotearoa/New Zealand from 1949-1995 (Unpublished doctoral dissertation). Massey University, Palmerston North, New Zealand

Power, M. K. (2003) Auditing and the production of legitimacy. Accounting, Organizations and Society, 28, 4, 379-394

Ryan, M., Habibis, D. and Craft, C. (1997) Guarding the gates of the profession: Findings of a survey of gatekeeping mechanisms in Australian Bachelor of Social Work programs. Australian Social Work, 50, 3, 5-12

Smith, E. (2008) Pitfalls and promises: The use of secondary data analysis in educational reseearch. British Journal of Educational Studies, 56, 3, 323-339

SWRB. (2011) Mandatory social worker registration: A discussion paper. Wellington, New Zealand

SWRB. (2013) Practicum within a recognised social work qualification. Wellington, New Zealand

Wayne, J., Bogo, M. and Raskin, M. (2010) Field education as the signature

39 J. of Practice Teaching \& Learning 13(1), pp.24-43. DOI: 10.1921/12302130106. @ w\&bb 2014 
pedagogy of social work education. Journal of Social Work Education, 46, 3, 327-339

Wilson, G. (2012) Reforming social work education: Some reflections on the contribution of practice learning. practice: Social Work in Action, 24, 4, 225-237

40 J. of Practice Teaching \& Learning 13(1), pp.24-43. DOI: 10.1921/12302130106. @ w\&b 2014 


\section{Appendix: Tables}

Table 1

Placement Survey Participants SWRB Recognised Providers

\begin{tabular}{lccc}
\hline & Total & \multicolumn{2}{c}{ Participants } \\
\hline & $\mathrm{n}$ & $\mathrm{n}$ & $\%$ \\
\hline Universities & 5 & 3 & 60 \\
Polytechnics & 8 & 4 & 50 \\
Wānanga & 2 & 0 & 0 \\
Total & 15 & 7 & 47 \\
\hline
\end{tabular}

Table 2

Placement by Agency Setting: SWRB Annual Report Data

\begin{tabular}{lrr}
\hline Agency Setting & $\mathrm{n}$ & $\%$ \\
\hline Non-government & 701 & 70 \\
Government & 301 & 30 \\
Total & 1002 & 100 \\
\hline
\end{tabular}

Table 3

Placements by Agency Setting: Survey Data

\begin{tabular}{lcr}
\hline Agency Setting & $\mathrm{n}$ & $\%$ \\
\hline Non-government & 272 & 55 \\
Government & 221 & 45 \\
Total & 493 & 100 \\
\hline
\end{tabular}

Table 4

Student Supervisors by Agency Setting: SWRB Annual Report Data

\begin{tabular}{lrr}
\hline Agency Setting & $\mathrm{n}$ & $\%$ \\
\hline Non-government & 1066 & 66 \\
Government & 547 & 34 \\
Total & 1613 & 100 \\
\hline
\end{tabular}

41 J. of Practice Teaching \& Learning 13(1), pp.24-43. DOI: 10.1921/12302130106. ( ) wEb 2014 
Table 5

RSW Supervisors by Placement Agency Setting: SWRB Annual Report Data

\begin{tabular}{lccccc}
\hline & \multicolumn{2}{c}{ RSW } & \multicolumn{2}{c}{ Non-RSW } & Total \\
Agency Setting & $\mathrm{n}$ & $\%$ & $\mathrm{n}$ & $\%$ & \\
\hline Non-government & 446 & 42 & 620 & 58 & 1066 \\
Government & 417 & 76 & 130 & 24 & 547 \\
Total & 863 & 54 & 750 & 46 & 1613 \\
\hline
\end{tabular}

Table 6

RSW Supervisors by Placement Agency Setting: Survey Data

\begin{tabular}{lccccc}
\hline & \multicolumn{2}{c}{ RSW } & \multicolumn{2}{c}{ Non-RSW } & Total \\
Agency Setting & $\mathrm{n}$ & $\%$ & $\mathrm{n}$ & $\%$ & \\
\hline Non-government & 144 & 53 & 128 & 47 & 272 \\
Government & 192 & 85 & 34 & 15 & 226 \\
Total & 336 & 67 & 162 & 33 & 498 \\
\hline
\end{tabular}

Table 7

On-site Supervisors by Placement Agency Setting: SWRB Annual Report Data

\begin{tabular}{lrrrrr}
\hline & \multicolumn{2}{c}{ On site } & \multicolumn{2}{c}{ Off site } & Total \\
Agency Setting & $\mathrm{n}$ & $\%$ & $\mathrm{n}$ & $\%$ & \\
\hline & & & & & \\
Non-government & 828 & 78 & 238 & 22 & 1066 \\
Government & 448 & 82 & 99 & 18 & 547 \\
Total & 1276 & 79 & 337 & 21 & 1613 \\
\hline
\end{tabular}

Table 8

On-site Supervisors by Placement Agency Setting: Survey Data

\begin{tabular}{lccrcc}
\hline & \multicolumn{2}{c}{ On site } & \multicolumn{2}{c}{ Off site } & \multirow{2}{*}{ Total } \\
Agency Setting & $\mathrm{n}$ & $\%$ & $\mathrm{n}$ & $\%$ & \\
\hline Non-government & 161 & 59 & 111 & 41 & 272 \\
Government & 170 & 75 & 56 & 25 & 226 \\
Total & 331 & 67 & 167 & 34 & 498 \\
\hline
\end{tabular}

42 J. of Practice Teaching E Learning 13(1), pp.24-43. DOI: 10.1921/12302130106. () wEb 2014 
Difficulties in mapping the demand for social work placements in New Zealand

Table 9

On-site RSW Supervisors by Placement Agency Setting: SWRB Annual Report Data

\begin{tabular}{lrrrrr}
\hline & \multicolumn{2}{c}{ On site } & \multicolumn{2}{c}{ Off site } & Total \\
Agency Setting & $\mathrm{n}$ & $\%$ & $\mathrm{n}$ & $\%$ & \\
\hline Non-government & 246 & 23 & 820 & 77 & 1066 \\
Government & 359 & 66 & 188 & 34 & 547 \\
Total & 605 & 38 & 1008 & 62 & 1613 \\
\hline
\end{tabular}

43 J. of Practice Teaching \& Learning 13(1), pp.24-43. DOI: 10.1921/12302130106. @ wE-b 2014 